\title{
Structure and properties of the $\mathrm{Na}_{2} \mathrm{~S}-\mathrm{P}_{2} \mathrm{~S}_{5}$ glasses and glass-ceramics prepared by mechanical milling
}

Kousuke Noi, Akitoshi Hayashi, and Masahiro Tatsumisago

Department of Applied Chemistry, Graduate School of Engineering,

Osaka Prefecture University, 1-1 Gakuencho, Naka-ku, Sakai, Osaka 599-8531, Japan

\section{Corresponding author:}

Akitoshi Hayashi (Associate Professor)

Department of Applied Chemistry, Graduate School of Engineering,

Osaka Prefecture University,

1-1 Gakuen-cho, Naka-ku, Sakai, Osaka 599-8531, JAPAN

Tel.: +81-72-2549331; Fax.: +81-72-2549334

E-mail address: hayashi@chem.osakafu-u.ac.jp. 


\section{Abstract}

The $x \mathrm{Na}_{2} \mathrm{~S} \cdot(100-x) \mathrm{P}_{2} \mathrm{~S}_{5}(\mathrm{~mol} \% ; \quad x=67,70,75$ and 80$)$ glasses were prepared by mechanochemical processing. Composition dependence of local structure, thermal behavior and electrical conductivity of the prepared glasses were examined. NMR and Raman spectroscopic studies revealed that the $x \mathrm{Na}_{2} \mathrm{~S} \cdot(100-x) \mathrm{P}_{2} \mathrm{~S}_{5}$ glasses were composed of the thiophosphate units corresponding to their nominal compositions. The room temperature conductivities of the glasses increased with an increase in the $\mathrm{Na}_{2} \mathrm{~S}$ content and attained a maximum at the $x=80$ composition; the highest conductivity is $1 \times 10^{-5} \mathrm{~S} \mathrm{~cm}^{-1}$. The $x \mathrm{Na}_{2} \mathrm{~S} \cdot(100-x) \mathrm{P}_{2} \mathrm{~S}_{5}$ glass-ceramics were obtained by heating the glasses beyond their crystallization temperatures. The relationship between conductivity and crystalline phase was studied for the glass-ceramics. The glass-ceramics at the compositions of $x=70$ and 75 exhibited higher conductivities than those of corresponding glasses due to the precipitation of the superionic cubic $\mathrm{Na}_{3} \mathrm{PS}_{4}$ crystal. In particular, the $x=75$ glass-ceramic showed the highest conductivity of $2 \times 10^{-4} \mathrm{~S} \mathrm{~cm}^{-1}$ at $25^{\circ} \mathrm{C}$ and the lowest activation energy of $27 \mathrm{~kJ}$ $\mathrm{mol}^{-1}$. In addition, the $x=75$ glass-ceramic was electrochemically stable against sodium deposition and dissolution. The $75 \mathrm{Na}_{2} \mathrm{~S} \cdot 25 \mathrm{P}_{2} \mathrm{~S}_{5}$ glass-ceramic electrolyte with high conductivity and high electrochemical stability is suitable for all-solid-state sodium rechargeable batteries.

Keywords: solid electrolyte, sulfide, glass-ceramic, sodium ion conductor, all-solid-state battery 


\section{Introduction}

Sodium rechargeable batteries, harnessing abundant and low-cost sodium resources, have been attracted as future versatile power sources that store renewable solar and wind energy at individual houses and large-scale power plants [1,2]. For example, sodium-sulfur (NAS) batteries have been already commercialized for large-scale storage, due to the high energy densities of about $760 \mathrm{Wh} \mathrm{kg}^{-}$

${ }^{1}$ [3]. NAS batteries, however, need to operate at temperatures higher than $300^{\circ} \mathrm{C}$ to use molten sulfur as a positive electrode and molten sodium as a negative electrode and to ensure the effective ionic transport between those electrodes and $\beta$-alumina ceramic body as a solid electrolyte. Liquid-state sodium and sulfur are so reactive, and molten polysulfides as discharge products are so corrosive that NAS batteries are manufactured with sophisticated engineering and expensive durable materials $[4,5]$, and utilized mainly in industrial or commercial facilities under a tight monitoring [6,7]. The above configurations of the present sodium-sulfur batteries must restrict their widespread application for household storages. On the other hand, the cell reactions of the traditional sodium-sulfur batteries are as follows [3]:

$$
\begin{aligned}
& x \mathrm{~S}+2 \mathrm{Na} \Leftrightarrow \mathrm{Na}_{2} \mathrm{~S}_{x}(x=5-3), \\
& E=2.08-1.78 \mathrm{~V} \text { at } 350^{\circ} \mathrm{C}
\end{aligned}
$$

The cells operate in the above $x$ range to keep the electrode materials molten state. While the cell is discharged to $x=2$, solid $\mathrm{Na}_{2} \mathrm{~S}_{2}$ forms and increases the cell resistance to stop any more discharge 
reaction. Thus the available capacity of the cell is limited to $\sim 557 \mathrm{mAh} \mathrm{g}^{-1}$ for sulfur in the above operation condition although the theoretical specific capacity of sulfur is $\sim 1672 \mathrm{mAh} \mathrm{g}^{-1}$ assuming a two-electron reaction.

All-solid-state sodium secondary batteries using sulfide solid electrolytes are alternative power sources for the next generation to overcome the applicable and energetic limits of the present sodium-sulfur batteries. Because research into the all-solid-state lithium batteries of past three decades has proved that solidification of rechargeable batteries is of worth in terms of safety, long cycle life, versatile geometries and energy density [8-12]. All-solid-state batteries which operate at ambient temperature are the safest batteries, because they do not suffer from leakage, volatilization, or flammability. These batteries are often composed of sulfide glass-based materials. Sulfide electrolytes have the favorable mechanical properties for fabricating all-solid-state batteries [13]; grain-boundary resistance can be remarkably decreased by only cold press without high temperature sintering, which is suitable for forming close solid-solid interfaces between electrode and electrolyte in all-solid-state batteries. We reported that the all-solid-state lithium cells $\mathrm{In} / \mathrm{Li}_{2} \mathrm{~S}-\mathrm{P}_{2} \mathrm{~S}_{5}$ glass-based electrolyte/ $/ \mathrm{LiCoO}_{2}$ exhibited excellent cycling performance of over 500 times with no decrease in the discharge capacity [12]. They worked under very high current densities of $10 \mathrm{~mA} \mathrm{~cm}{ }^{-2}$ when oxide- or sulfide-coated $\mathrm{LiCoO}_{2}$ particles were used as an active material $[14,15]$. On the other hand, the all-solid-state lithium-sulfur cells using these sulfide glass-based electrolytes exhibited 
high discharge-charge capacities of over $1000 \mathrm{mAh}$ per gram of sulfur, indicating the reversible electrode reactions involving the discharge products of $\mathrm{Li}_{2} \mathrm{~S}$ [16]. Hence solidification of sodium-sulfur batteries generates the novel rechargeable batteries with several advantages of high safety, high energy density, and low material cost. The key materials to realize those advanced batteries are the solid electrolytes that have high $\mathrm{Na}^{+}$ion conductivities at room temperature and form close solid-solid interfaces between electrode and electrolyte: these are, for example, sulfide glass-base materials.

Recently, we have reported that a cubic $\mathrm{Na}_{3} \mathrm{PS}_{4}$ phase as a superionic crystal was precipitated by crystallization of the $75 \mathrm{Na}_{2} \mathrm{~S} \cdot 25 \mathrm{P}_{2} \mathrm{~S}_{5}\left(\mathrm{~mol} \%, \mathrm{Na}_{3} \mathrm{PS}_{4}\right)$ sulfide glass obtained by mechanical milling [17]. The powder-compressed $\mathrm{Na}_{3} \mathrm{PS}_{4}$ glass-ceramic electrolyte exhibited the high sodium ion conductivity of over $10^{-4} \mathrm{~S} \mathrm{~cm}^{-1}$ at ambient temperature. All-solid-state sodium batteries $\left(\mathrm{Na}-\mathrm{Sn} / \mathrm{TiS}_{2}\right)$ with the $\mathrm{Na}_{3} \mathrm{PS}_{4}$ glass-ceramic electrolyte successfully operated as a rechargeable battery at room temperature [17]. In order to apply the $\mathrm{Na}_{3} \mathrm{PS}_{4}$ glass-ceramic electrolyte to other type of batteries such as $\mathrm{Na} / \mathrm{S}$ and to improve cell performances, it is important to optimize the composition ranges of the $\mathrm{Na}_{2} \mathrm{~S}-\mathrm{P}_{2} \mathrm{~S}_{5}$ binary glasses to obtain the cubic $\mathrm{Na}_{3} \mathrm{PS}_{4}$ crystal. Characterizations of structure and electrical conductivity of the glasses and glass-ceramics which have compositions close to $\mathrm{Na}_{3} \mathrm{PS}_{4}$ are useful to find suitable solid electrolytes for all-solid-state batteries. 
In this study, composition dependence of thermal and electrical properties, and local structure of the $x \mathrm{Na}_{2} \mathrm{~S} \cdot(100-x) \mathrm{P}_{2} \mathrm{~S}_{5}(\mathrm{~mol} \%, x=67,70,75$ and 80$)$ glasses was examined. The relationship between conductivity and crystalline phase was studied for glass-ceramics prepared by crystallization of parent glasses. The electrochemical stability against sodium metal was evaluated for the glass-ceramic electrolytes.

\section{Experimental}

The $x \mathrm{Na}_{2} \mathrm{~S} \cdot(100-x) \mathrm{P}_{2} \mathrm{~S}_{5}(\mathrm{~mol} \%, x=67,70,75$ and 80$)$ glasses were prepared by a mechanochemical technique using a planetary ball mill (Fritsch, Pulverisette 7) in the same manner as reported [17]. Starting materials, the reagent-grade $\mathrm{Na}_{2} \mathrm{~S}$ (Sigma-Aldrich Co.) and $\mathrm{P}_{2} \mathrm{~S}_{5}$ (Sigma-Aldrich Co.) crystalline powders were weighted and mixed in appropriate molar ratios in an agate motor. The mixture was then placed into a zirconia $\left(\mathrm{ZrO}_{2}\right)$ vessel (internal volume of $45 \mathrm{~mL}$ ) with $500 \mathrm{ZrO}_{2}$ balls (4 mm in diameter). Mechanical milling was performed for $20 \mathrm{~h}$ at a fixed rotation speed of the base disk of $510 \mathrm{rpm}$. The glass-ceramics were prepared by heating the glasses at the temperatures above their crystallization temperatures. All processes were performed in a dry $\mathrm{Ar}$ atmosphere.

X-ray diffraction (XRD) measurements of the prepared materials were performed to identify the crystalline phases, using $\mathrm{CuK} \alpha$ with a laboratory X-ray diffractometer (Rigaku, Ultima IV). 
Raman spectra of the glasses were obtained using the $514 \mathrm{~nm}$ line of an Ar laser with a Raman spectrophotometer (Jasco, NR-1000). Solid-state ${ }^{31}$ P MAS-NMR measurements were conducted to investigate the local structure around phosphorus atom, using a NMR spectrometer (Varian, Unity Inova 300). A single pulse sequence with $\pi / 2$ pulse of $2.0 \mu$ s was used. A cycle pulse delay was $5.0 \mathrm{~s}$ and the $85 \%$ of $\mathrm{H}_{3} \mathrm{PO}_{4}$ aqueous solution was used as a standard. A cylindrical zirconia spinner containing the samples was rotated at a speed of about $5 \mathrm{kHz}$ during the MAS-NMR measurements. Differential thermal analysis (DTA) was performed by using a thermal analyzer (Rigaku, Thermo Plus TG8110) at a heating rate of $10^{\circ} \mathrm{C} \min ^{-1}$.

Electrical conductivities of the glasses and glass-ceramics were measured for the pelletized samples with about $10 \mathrm{~mm}$ in diameter and $1-1.5 \mathrm{~mm}$ in thickness. Carbon paste was painted to form electrodes on both faces of the pellets. Two stainless-steel disks coupled with Pt wires were attached to the pellets as a current collector. AC impedance measurements were performed for the obtained two-electrode cell in a dry Ar gas atmosphere using an impedance analyzer (Solartron, 1260). Impedance was measured in the frequency range of $0.1 \mathrm{~Hz}$ to $8 \mathrm{MHz}$ at temperatures from ambient to above crystallization temperature. The conductivities of glasses were calculated from the impedances in the heating process and those of glass-ceramics were from the impedances in the cooling process.

A galvanostatic polarization test using the symmetric cell $\mathrm{Na} /$ glass-ceramic electrolyte/ $\mathrm{Na}$ was 
carried out to investigate the electrochemical stability of the glass-ceramics against sodium deposition and dissolution. The $75 \mathrm{Na}_{2} \mathrm{~S} \cdot 25 \mathrm{P}_{2} \mathrm{~S}_{5}$ glass-ceramic powder obtained by heating the mother glass at $270^{\circ} \mathrm{C}$ for $2 \mathrm{~h}$ was placed in a 10 -mm-diameter polycarbonate tube and compressed to prepare the pellet with $80 \mu \mathrm{m}$ in thickness. Sodium foils were attached on the both sides of the pellet. The three-layered pellet was sandwiched between two stainless-steel rods as current collectors. The direct current of a constant current density of $0.013 \mathrm{~mA} \mathrm{~cm}^{-2}$ for $0.5 \mathrm{~h}(\mathrm{ca} 0.018 \mathrm{C})$ was applied for the cell fabricated; the current direction was alternated for 10 times. The measurement was performed at room temperature under an Ar atmosphere using a charge-discharge measurement device (Nagano, BTS-2004).

\section{Results and discussion}

Fig. 1 shows X-ray diffraction (XRD) patterns of the $x \mathrm{Na}_{2} \mathrm{~S} \cdot(100-x) \mathrm{P}_{2} \mathrm{~S}_{5}(\mathrm{~mol} \%, x=67,70,75$ and 80) samples obtained by mechanical milling of the two crystalline starting materials for $20 \mathrm{~h}$. Halo patterns were basically observed for all samples, although weak diffraction peaks due to the $\mathrm{Na}_{2} \mathrm{~S}$ crystal were present in the composition of $x=80$. As described below, all the samples exhibited glass transition phenomena by thermal analysis. There have been several reports about the glass-forming compositions in the system $x \mathrm{Na}_{2} \mathrm{~S} \cdot(100-x) \mathrm{P}_{2} \mathrm{~S}_{5}$ prepared by melt quenching or mechanical milling [18-20]. Maier et al. and Ribes et al have respectively reported that the X-ray 
amorphous range of the melt-quenched samples, in this binary system, were $0 \leq x \leq 78[18]$ and $0 \leq$ $x \leq 66$ [19]. On the other hand, Berbano et al have reported that the mechanochemically-treated $x \mathrm{Na}_{2} \mathrm{~S} \cdot(100-x) \mathrm{P}_{2} \mathrm{~S}$ samples became amorphous at the compositions less than $70 \mathrm{~mol} \% \mathrm{Na}_{2} \mathrm{~S}$, and the tetragonal $\mathrm{Na}_{3} \mathrm{PS}_{4}$ crystal which is a thermodynamically stable phase at ambient temperature was formed at $x=75$ [20]. Glass-forming regions often vary depending on the preparation conditions such as the cooling rate of melt, the mechanical force applied to reactants, and the purity of starting materials. These factors would accelerate the glass formation due to the enhancement of the driving force for amorphization or the expansion of amorphous region in a multi-component system with incorporating trace amounts of impurities.

Local structure of these mechanically milled glasses was investigated by Raman and ${ }^{31} \mathrm{P}$ MAS-NMR spectroscopies. Raman spectra of the $x \mathrm{Na}_{2} \mathrm{~S} \cdot(100-x) \mathrm{P}_{2} \mathrm{~S}_{5}$ mechanically milled glasses were presented in fig. 2. A main band was observed at $420 \mathrm{~cm}^{-1}$ at the compositions of $x=75$ and $x=80$. Two large bands at 420 and $400 \mathrm{~cm}^{-1}$ and a small band at $380 \mathrm{~cm}^{-1}$ were observed at the $x=70$ composition. A main band was observed at $400 \mathrm{~cm}^{-1}$ in the composition of $x=67$. These peaks are assigned on the basis of the literatures about lithium thiophosphates, because systematic investigations about the local structures of sodium thiophosphates have not been reported in detail. Tachez et al. have reported the Raman spectra of the crystalline and glassy $\mathrm{Li}_{2} \mathrm{~S}-\mathrm{P}_{2} \mathrm{~S}_{5}$ systems; the peaks at 418, 406 and $382 \mathrm{~cm}^{-1}$ are attributed to the P-S stretching modes of the thiophosphate ions 
in the $\mathrm{Li}_{3} \mathrm{PS}_{4}$ crystal, the $\mathrm{Li}_{4} \mathrm{P}_{2} \mathrm{~S}_{7}$ glass, and the $\mathrm{Li}_{4} \mathrm{P}_{2} \mathrm{~S}_{6}$ crystal, respectively [21]. Based on this report, the three peaks observed in the Fig. 2 were assigned to the several thiophosphate ions as a counterpart of sodium ions as follows: the peak at $420 \mathrm{~cm}^{-1}$ is attributable to $\mathrm{PS}_{4}{ }^{3-}$ ions, $400 \mathrm{~cm}^{-1}$ to $\mathrm{P}_{2} \mathrm{~S}_{7}{ }^{4-}$, and $380 \mathrm{~cm}^{-1}$ to $\mathrm{P}_{2} \mathrm{~S}_{6}^{4-}$. Thus the sodium richer glasses of the $x=80$ (nominally $\left.\mathrm{Na}_{3} \mathrm{PS}_{4}+0.5 \mathrm{Na}_{2} \mathrm{~S}\right)$ and $x=75\left(\mathrm{Na}_{3} \mathrm{PS}_{4}\right)$ compositions were mainly composed of $\mathrm{PS}_{4}{ }^{3-}$ ion, while the sodium poorer glass of the $x=67\left(\mathrm{Na}_{4} \mathrm{P}_{2} \mathrm{~S}_{7}\right)$ composition was mainly composed of $\mathrm{P}_{2} \mathrm{~S}_{7}{ }^{4-}$ ions. In the intermediate $x=70 \quad\left(0.5 \mathrm{Na}_{3} \mathrm{PS}_{4}+0.5 \mathrm{Na}_{4} \mathrm{P}_{2} \mathrm{~S}_{7}\right)$ composition, $\mathrm{PS}_{4}{ }^{3-}$ and $\mathrm{P}_{2} \mathrm{~S}_{7}{ }^{4-}$ ions were major components and $\mathrm{P}_{2} \mathrm{~S}_{6}{ }^{4-}$ ions partially existed. The Raman spectroscopy revealed that the mechanically milled $\mathrm{Na}_{2} \mathrm{~S}-\mathrm{P}_{2} \mathrm{~S}_{5}$ glasses were composed of thiophosphate ions corresponding to each nominal composition.

Fig. 3 shows the ${ }^{31} \mathrm{P}$ MAS-NMR spectra of the $x \mathrm{Na}_{2} \mathrm{~S} \cdot(100-x) \mathrm{P}_{2} \mathrm{~S}_{5}$ mechanically milled glasses. The spectra for the $x=75$ and 80 compositions exhibited a single peak at about $84 \mathrm{ppm}$. The $x=67$ glass showed the spectrum with a broad peak at about $93 \mathrm{ppm}$. For the $x=70$ composition, there was a broad peak composed of at least three components at about 84,93 , and $107 \mathrm{ppm}$. In the lithium thiophosphate glasses, the peaks attributed to the $\mathrm{PS}_{4}$ tetrahedral unit, the $\mathrm{P}_{2} \mathrm{~S}_{7}$ unit with a bridging-sulfur, and the $\mathrm{P}_{2} \mathrm{~S}_{6}$ unit with a P-P bond, appear at 83, 90 and $109 \mathrm{ppm}$, respectively [22-24]. Therefore, the peaks at about 84, 93 and $107 \mathrm{ppm}$ as shown in Fig. 3 are respectively attributable to the $\mathrm{PS}_{4}, \mathrm{P}_{2} \mathrm{~S}_{7}$ and $\mathrm{P}_{2} \mathrm{~S}_{6}$ units in the sodium thiophosphate glasses. Structural 
assignment by NMR is in good agreement with that by Raman spectroscopy. In addition, there was no peak in the region of $-50 \leq \delta \leq 70$ where the peaks derived from the phosphate units with P-O bonds are observed $[25,26]$, indicating that oxygen contamination is negligible in the glasses.

Fig. 4 shows the differential thermal analysis (DTA) curves of the $x \mathrm{Na}_{2} \mathrm{~S} \cdot(100-x) \mathrm{P}_{2} \mathrm{~S}_{5}$ mechanically milled glasses. For all the compositions, the endothermic phenomena due to glass transitions were observed clearly at the low-temperature sides of the exothermic peaks derived from crystallizations. The glass transition temperatures of the glasses were around $180-190^{\circ} \mathrm{C}$, and the first crystallization temperatures were around $190-220^{\circ} \mathrm{C}$. These glasses exhibited the complicated behavior of crystallizations and/or phase transitions except at the $x=67$ composition. Each glass was heated to the temperatures denoted with an arrow in the Fig. 4, which are above the first crystallization temperatures and sufficiently below the isolated second peak, to obtain the glass-ceramics. Heat treatments were performed for the powder-compressed pellets. Impedances of the pellets were measured at various stages of the heating and cooling processes.

Temperature dependence of the total conductivities for the $x \mathrm{Na}_{2} \mathrm{~S} \cdot(100-x) \mathrm{P}_{2} \mathrm{~S}_{5}$ glasses and glass-ceramics were presented in Fig. 5. A single impedance components, which could not be separated to bulk and grain boundary components, were observed in all the Nyquist plots of the pelletized sample. Open and closed circles respectively denote conductivities on heating and cooling processes. For the $x=80$ composition (d), the conductivities were decreased by an order of 
magnitude due to crystallization. On the other hand, the conductivities were drastically increased by crystallization for the $x=75$ (c) and $x=70$ (b) compositions. The conductivities before and after crystallization were almost the same at the $x=67$ composition (a). The conductivities of the glasses and glass-ceramics obeyed the Arrhenius equation, and the activation energies for conduction were calculated in the temperature ranges from 25 to $150^{\circ} \mathrm{C}$.

Fig. 6 shows the composition dependences of the room temperature conductivities $\left(\sigma_{25}\right)$ and the activation energies $\left(\mathrm{E}_{\mathrm{a}}\right)$ for the glassy and glass-ceramic samples. The conductivities of the $x \mathrm{Na}_{2} \mathrm{~S} \cdot$ $(100-x) \mathrm{P}_{2} \mathrm{~S}_{5}$ glasses increased with an increase in the $\mathrm{Na}_{2} \mathrm{~S}$ content $(x)$ as the source of sodium ion carrier. The activation energies of these glasses exhibited almost the same values, i.e. 41-48 kJ $\mathrm{mol}^{-1}$. Thus the increase of the conductivity is mainly resulted from the increase of career concentration. The highest room temperature conductivity of $1 \times 10^{-5} \mathrm{~S} \mathrm{~cm}^{-1}$ was obtained at the $x=80$ composition. In contrast to the glass, the glass-ceramics showed the non-monotonic change of the conductivity with respect to composition, suggesting that precipitated crystalline phases influence the conductivities. The $x=70$ and $x=75$ glass-ceramics exhibited higher conductivities than the parent glasses. Correspondingly, the activation energies were decreased by crystallization at these compositions. The $x=75$ glass-ceramic exhibited the highest room temperature conductivity of $2 \times 10^{-4} \mathrm{~S} \mathrm{~cm}^{-1}$ and the lowest activation energy of $27 \mathrm{~kJ} \mathrm{~mol}^{-1}$, as shown in the previous report [17]. The crystal and local structures of the glass-ceramics were investigated to 
discuss composition dependence of conductivities.

Fig. 7 shows the XRD patterns of the glass-ceramics obtained after impedance measurements.

The tetragonal $\mathrm{Na}_{3} \mathrm{PS}_{4}$ crystal was precipitated as main phase in the glass-ceramic of $x=80$ composition. The ambient temperature conductivity of tetragonal-Na $\mathrm{PS}_{4}$ was reported as $1 \times 10^{-6} \mathrm{~S}$ $\mathrm{cm}^{-1}[27]$. This conductivity value is comparable to that of the $x=80$ glass-ceramic. On the other hand, the cubic $\mathrm{Na}_{3} \mathrm{PS}_{4}$ crystal were precipitated in the $x=75$ and 70 glass-ceramics that showed higher conductivities compared to those of glasses prior to crystallization. We have reported that the cubic phase of $\mathrm{Na}_{3} \mathrm{PS}_{4}$ is the high temperature phase with superionic conductivity [17]. For the $x=70$ composition, unknown peaks were also observed in the XRD pattern. These unknown reflections were observed more clearly in the $x=67$ glass-ceramic that showed a fairly lower conductivity than the $\mathrm{x}=75$ glass-ceramic. The unknown phase would have the relative low conductivity of about $10^{-6} \mathrm{~S} \mathrm{~cm}^{-1}$ at ambient temperature. The mixture of cubic $\mathrm{Na}_{3} \mathrm{PS}_{4}$ and the unknown phase is accountable for the lower conductivity of the $x=70$ glass-ceramic compared to the $\mathrm{x}=75$ glass-ceramic. The investigation of crystalline phases described above leads to the prediction that the best composition in $67 \leq \mathrm{x} \leq 80$ is $x=75$ in terms of the room temperature conductivity. Future study on the $75 \mathrm{Na}_{2} \mathrm{~S} \cdot 25 \mathrm{P}_{2} \mathrm{~S}_{5}$ glass-ceramic about the crystallite size and the volumetric fraction of cubic $\mathrm{Na}_{3} \mathrm{PS}_{4}$ is needed for further increase in conductivity.

Fig. 8 shows the ${ }^{31} \mathrm{P}$ MAS-NMR spectra of the $x \mathrm{Na}_{2} \mathrm{~S} \cdot(100-x) \mathrm{P}_{2} \mathrm{~S}_{5}$ glass-ceramics. The peak 
attributable to the $\mathrm{PS}_{4}$ tetrahedral unit was observed at $87 \mathrm{ppm}$ in the $x=80,75$ and 70 compositions.

These peaks shifted from the position in the parent glasses at 84 ppm (shown in Fig. 3). This implies that the local structure around phosphorus of the $\mathrm{PS}_{4}{ }^{3-}$ in the crystalline $\mathrm{Na}_{3} \mathrm{PS}_{4}$ would differ from those in the glassy states and the difference would have an effect upon the sodium ion conduction. This kind peak shift by a crystallization of a glass is also reported in the system $\mathrm{Li}_{2} \mathrm{~S}-\mathrm{P}_{2} \mathrm{~S}_{5}[24,28]$. The peak positions of the $\mathrm{PS}_{4}$ unit, in the $x=80$ glass-ceramic containing the tetragonal phase and the $x=75$ glass-ceramic containing the cubic phase, were almost the same, although there was slight difference in the sharpness of the $\mathrm{PS}_{4}$ peaks due to the small difference in the fraction of a residual glass component. For the $x=67$ glass-ceramic, there was the peak assignable to $\mathrm{P}_{2} \mathrm{~S}_{7}$ unit at $93 \mathrm{ppm}$, that would be equivalent to the peak at $92 \mathrm{ppm}$ in glass. This $\mathrm{P}_{2} \mathrm{~S}_{7}$ peak was also observed in the spectra of the $x=70$ glass-ceramic. From the XRD patterns and NMR spectra, it is expected that the unknown phase precipitated in the $\mathrm{x}=67$ and 70 glass-ceramics is the $\mathrm{Na}_{4} \mathrm{P}_{2} \mathrm{~S}_{7}$ crystal composed of $\mathrm{P}_{2} \mathrm{~S}_{7}{ }^{4-}$ ions.

Electrochemical stability is an important property of solid electrolytes to apply them to all-solid-state batteries. We reported that the $x=75$ glass-ceramic exhibited the wide electrochemical window of $5 \mathrm{~V}$ vs. $\mathrm{Na}^{+} / \mathrm{Na}[17]$. In the present study, the electrochemical stability of this electrolyte against sodium metal was investigated in more detail. The all-solid-state sodium symmetric cell was fabricated using the $x=75$ glass-ceramic and sodium metal foils. Fig. 9 shows 
the galvanostatic cycling of the cell $\mathrm{Na} / 75 \mathrm{Na}_{2} \mathrm{~S} \cdot 25 \mathrm{P}_{2} \mathrm{~S}_{5}$ glass-ceramic $/ \mathrm{Na}$ at room temperature.

The constant current was applied to the cell with the charge amount of $0.018 \mathrm{C}$, and then the same charge was applied to the opposite direction. The voltage profile showed the constant over voltage corresponding to the internal resistance of the cell for ten cycles. The constant cell voltage suggests that a resistive layer is not formed at the interface between the sodium metal and the solid electrolyte during sodium deposition and dissolution. The XRD pattern of the solid electrolyte extracted from the cell after the galvanometric 10 cycles is shown in Fig. 10 (a). The pattern is almost the same with that of the as-prepared glass-ceramic electrolyte (b), indicating that the $75 \mathrm{Na}_{2} \mathrm{~S} \cdot 25 \mathrm{P}_{2} \mathrm{~S}_{5}$ glass-ceramic has a high electrochemical stability against sodium metal. This glass-ceramic material with high conductivity and electrochemical stability is a suitable solid electrolyte in the $\mathrm{Na}_{2} \mathrm{~S}-\mathrm{P}_{2} \mathrm{~S}_{5}$ binary system for a high-performance all-solid-state sodium battery.

\section{Conclusions}

The $x \mathrm{Na}_{2} \mathrm{~S} \cdot(100-x) \mathrm{P}_{2} \mathrm{~S}_{5}(\mathrm{~mol} \%, 67 \leq \mathrm{x} \leq 80)$ glasses and glass-ceramics that composed of the thiophosphates ions corresponding to the nominal compositions were prepared by mechanical milling. The room temperature conductivities of the glass electrolytes increased with an increase in the $\mathrm{Na}_{2} \mathrm{~S}$ content and attained a maximum at the $x=80$ composition; the highest conductivity is $1 \times$ $10^{-5} \mathrm{~S} \mathrm{~cm}^{-1}$. The glass-ceramic electrolytes were obtained by heating glasses to over their 
crystallization temperatures. The glass-ceramics of the $x=70$ and 75 compositions exhibited one order of magnitude higher conductivities than those of the glasses, because the cubic $\mathrm{Na}_{3} \mathrm{PS}_{4}$ superionic crystal was precipitated in glass-ceramics. The maximum conductivity of the glass-ceramic at room temperature, $2 \times 10^{-4} \mathrm{~S} \mathrm{~cm}^{-1}$, and the lowest activation energy, $27 \mathrm{~kJ} \mathrm{~mol}^{-1}$, were observed at the composition of $x=75$. In addition, the $x=75$ glass-ceramic showed the excellent electrochemical stability against $\mathrm{Na}$ metal during sodium deposition and dissolution processes. The $75 \mathrm{Na}_{2} \mathrm{~S} \cdot 25 \mathrm{P}_{2} \mathrm{~S}_{5}$ glass-ceramic exhibiting the high room temperature conductivity and the high electrochemical stability is an appropriate solid electrolyte in the $\mathrm{Na}_{2} \mathrm{~S}-\mathrm{P}_{2} \mathrm{~S}_{5}$ binary system.

\section{Acknowledgements}

This research was supported by JST, "Advanced Low Carbon Technology Research and Development Program (ALCA)".

\section{References}

[1] K.B. Hueso, M. Armand and T. Rojo, Energy Environ. Sci. 6 (2013) 734-749.

[2] H. Pan, Y.-S. Hu and L. Chen, Energy Environ. Sci. 6 (2013) 2338-2360.

[3] X. Lu, G. Xia, J. P. Lemmon and Z. Yang, J. Power Sources 195 (2010) 2431-2422. 
[4] M. D. Slater, D. Kim, E. Lee and C. S. Johnson, Adv. Funct.Mater. 23 (2013) 947-958.

[5] X. Lu, B. W. Kirby, W. Xu, G. Li, J. Y. Kim, J. P. Lemmon, V. L. Sprenkle and Z. Yang, Energy Environ. Sci. 6 (2013) 299-306.

[6] Z. Wen, J. Cao, Z. Gu, X. Xu, F. Zhang and Z. Lin, Solid State Ionics 179 (2008) 1697-1701.

[7] http://www.ngk.co.jp/english/news/2012/0607.html (accessed March 2014).

[8] J. M. Tarascon and M. Armand, Nature 414 (2001) 359-367.

[9] N. Kamaya, K. Homma, Y. Yamakawa, M. Hirayama, R. Kanno, M. Yonemura, T. Kamiyama,

Y. Kato, S. Hama, K. Kawamoto and A. Mitsui, Nat. Mater. 10 (2011) 682-686.

[10] K. Takada, Acta Mater. 61 (2013) 759-770.

[11] M. Tatsumisago, M. Nagao and A. Hayashi, J. Asian Ceram. Soc. 1 (2013) 17-25.

[12] M. Tatsumsiago and A. Hayashi, Funct. Mater. Lett. 1 (2008) 31-36.

[13] A. Sakuda, A. Hayashi and M. Tatsumisago, Sci. Rep. 3 (2013) 2261:1-5.

[14] N. Ohta, K. Takada, L. Zhang, R. Ma, M. Osada and T. Sasaki Adv. Mater. 18 (2006) 2226-2229.

[15] A. Sakuda, N. Nakamoto, H. Kitaura, A. Hayashi, K. Tadanaga and M. Tatsumisago, J. Mater. Chem. 22 (2012) 15247-15254.

[16] M. Nagao, A. Hayashi and M. Tatsumisago, Electrochem. Commun. 22 (2012) 177-180.

[17] A. Hayashi, K. Noi, A. Sakuda, M. Tatsumisago, Nat.Commun. 3 (2012) 856: 1-5. 
[18] L. Maier and J. R. V. Wazer, J. Am. Chem. Soc., 84 (1962) 3054.

[19] M.Ribes, B. Barrau and J. L. Souquet, J. Non-Cryst. Solids, $38 \& 39$ (1980) 271.

[20] S.S. Berbano, I.Seo, C.M. Bischoff, K.E. SchullerandS.W. Martin, J. Non-Cryst. Solids, 358

(2012) 93.

[21] M. Tachez, J. P. Malugani, R. MercierandG. Robert, Solid State Ionics, 14(1984) 181.

[22] H. Eckert, Z. Zhang and J. H. Kennedy, Chem. Mater., 2 (1990) 279.

[23] A. Hayashi, R. Araki, K. Tadanaga, M. Tatsumisago and T. Minami, Phys. Chem. Glasses,40 (1999) 140.

[24] F. Mizuno, T. Ohtomo, A. Hayashi, K. Tadanaga, T. Minami and M. Tatsumisago, J. Ceram. Soc. Jpn.,112 (2004) S709.

[25] L. B. Wüllen, H. Eckert and G. Schwering, Chem. Mater., 12 (2000) 1840.

[26] A. Hayashi, M. Tatsumisago and T. Minami, J. Electrochem. Soc., 146 (1999) 3472.

[27] M. Jansen, U. Henseler, J. Solid State Chem. 99 (1992) 110.

[28] K. Minami, F. Mizuno, A. Hayashi and M. Tatsumisago, J. Non-Cryst. Soids 354 (2008) 370. 


\section{Figure captions}

Fig. 1 XRD patterns of the mechanically milled $x \mathrm{Na}_{2} \mathrm{~S} \cdot(100-x) \mathrm{P}_{2} \mathrm{~S}_{5}(\mathrm{~mol} \%)$ glasses.

Fig. 2 Raman spectra of the mechanically milled $x \mathrm{Na}_{2} \mathrm{~S} \cdot(100-x) \mathrm{P}_{2} \mathrm{~S}_{5}$ glasses.

Fig. $3 \quad{ }^{31} \mathrm{P}$ MAS-NMR spectra of the mechanically milled $x \mathrm{Na}_{2} \mathrm{~S} \cdot(100-x) \mathrm{P}_{2} \mathrm{~S}_{5}$ glasses.

Fig. 4 DTA curves for the mechanically milled $x \mathrm{Na}_{2} \mathrm{~S} \cdot(100-x) \mathrm{P}_{2} \mathrm{~S}_{5}$ glasses. Heat treatment temperatures to prepare the glass-ceramic samples were also shown as arrows in the figure.

Fig. 5 Temperature dependence of the conductivities for the $x \mathrm{Na}_{2} \mathrm{~S} \cdot(100-x) \mathrm{P}_{2} \mathrm{~S}_{5}$ glasses (open circles in heating processes) and glass-ceramics (closed circles in cooling processes) ; (a) $x=67$, (b) $x=70$, (c) $x=75$ and (d) $x=80$.

Fig. 6 Composition dependence of the room temperature conductivities $\left(\sigma_{25}\right)$ and the activation energies $\left(\mathrm{E}_{\mathrm{a}}\right)$ for the $x \mathrm{Na}_{2} \mathrm{~S} \cdot(100-x) \mathrm{P}_{2} \mathrm{~S}_{5}$ glasses and glass-ceramics. Open and closed symbols denote the values for glasses and glass-ceramics, respectively.

Fig. 7 XRD patterns of the $x \mathrm{Na}_{2} \mathrm{~S} \cdot(100-x) \mathrm{P}_{2} \mathrm{~S}_{5}$ glass-ceramics. These samples were obtained after the impedance measurements as shown in Fig. 5.

Fig. $8 \quad{ }^{31}$ P MAS-NMR spectra of the $\mathrm{xNa}_{2} \mathrm{~S} \cdot(100-\mathrm{x}) \mathrm{P}_{2} \mathrm{~S}_{5}$ glass-ceramics.

Fig. 9 Galvanostatic cycling of the all-solid-state symmetric cell $\mathrm{Na} / 75 \mathrm{Na}_{2} \mathrm{~S} \cdot 25 \mathrm{P}_{2} \mathrm{~S}_{5}$ glass-ceramic / Na.

Fig. $10 \mathrm{XRD}$ pattern of the $75 \mathrm{Na}_{2} \mathrm{~S} \cdot 25 \mathrm{P}_{2} \mathrm{~S}_{5}$ solid electrolyte pellet extracted from the $\mathrm{Na}$ 
symmetric cell after the galvanometric cycles (a). The pattern of the as-prepared solid electrolyte pellet (b) was also shown for comparison. 


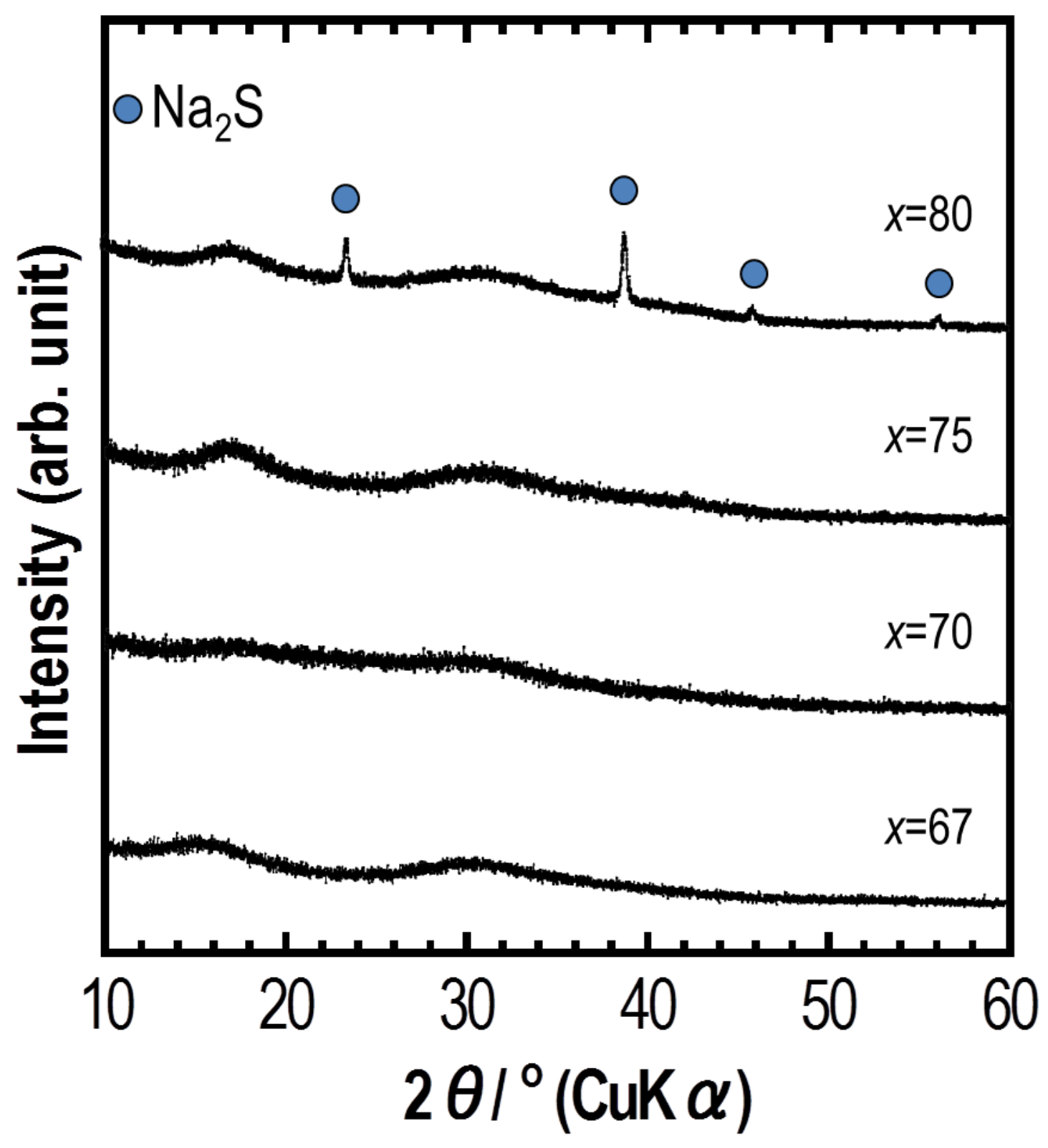

Fig. 1 


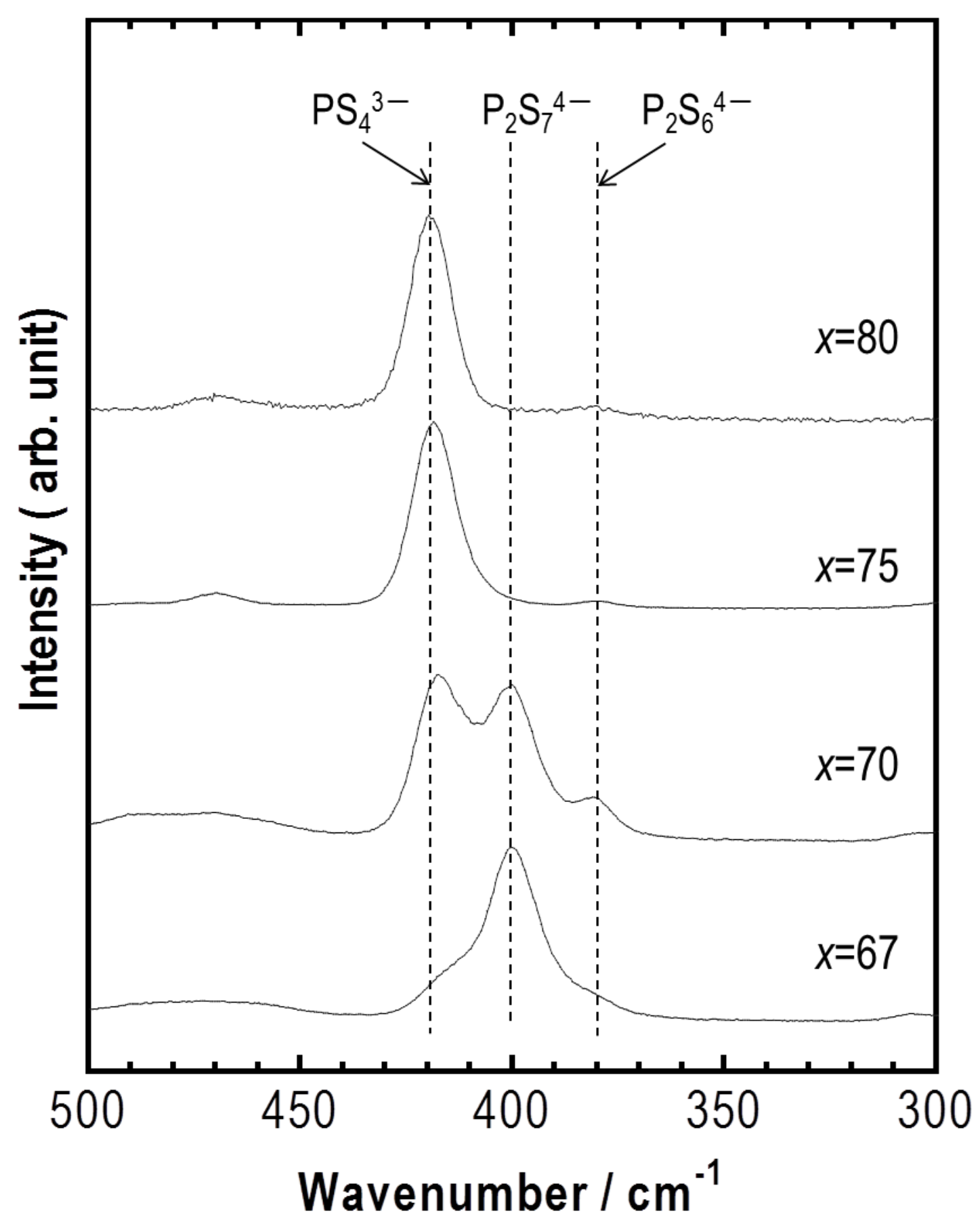

Fig. 2 


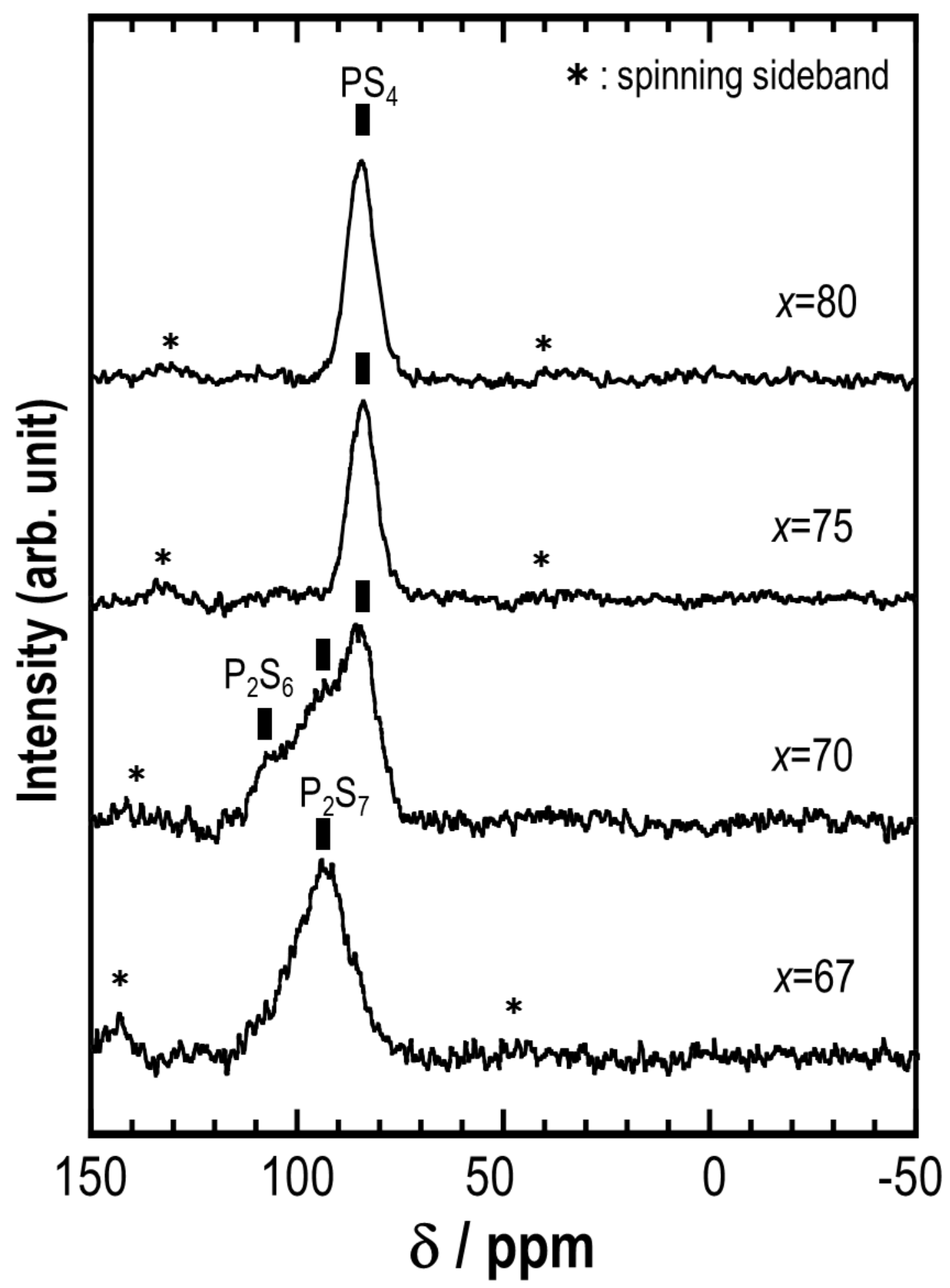

Fig. 3 


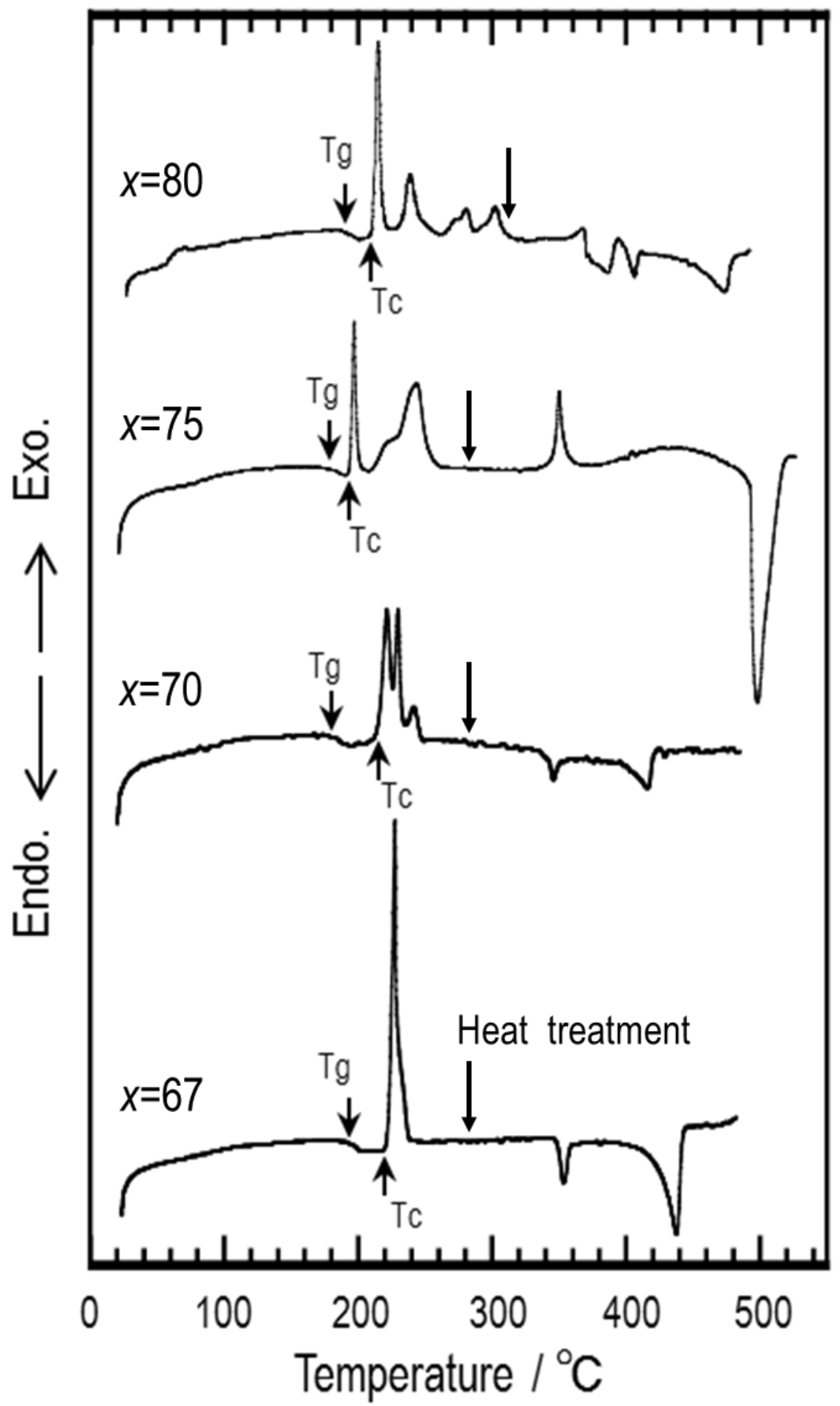

Fig. 4 

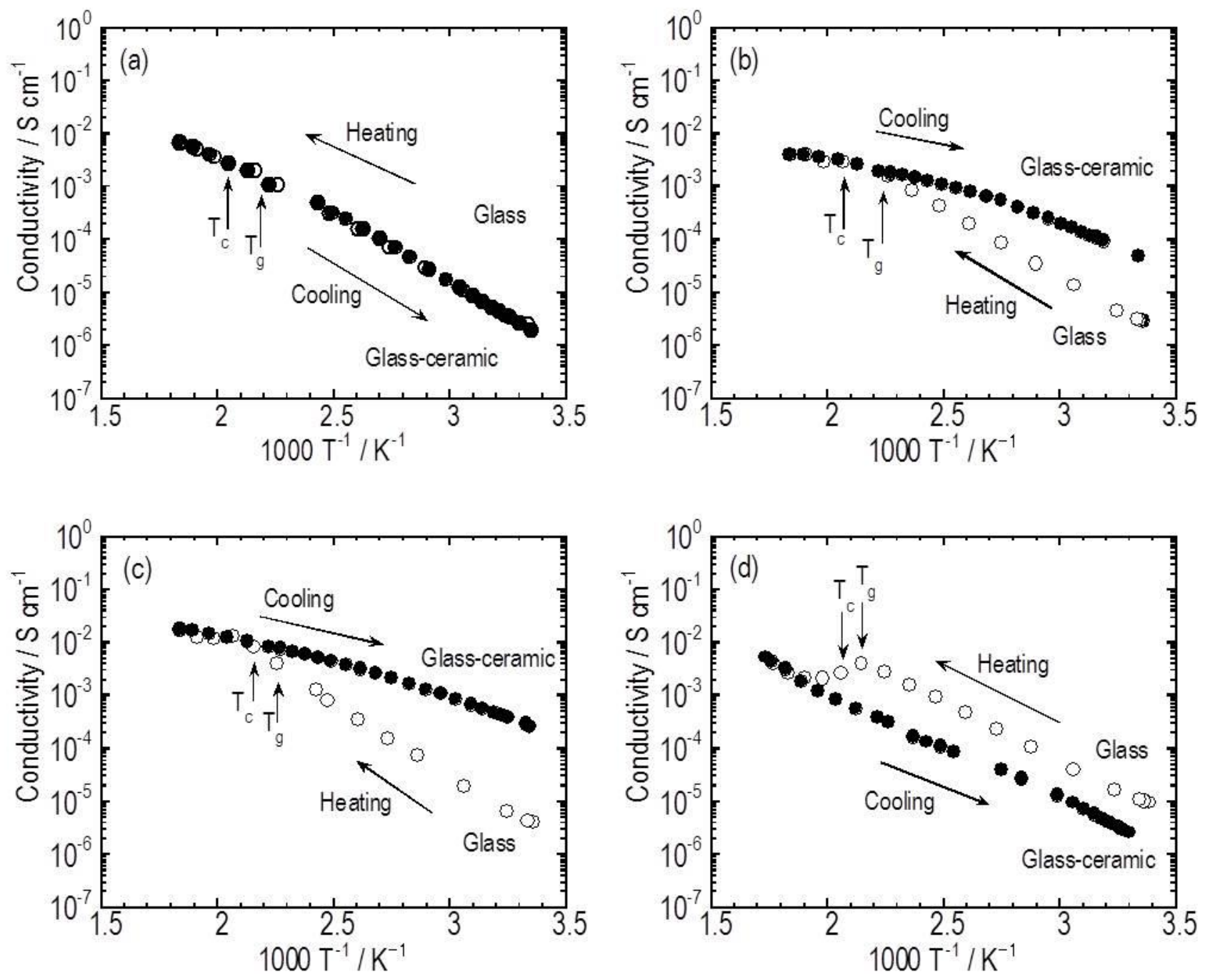

Fig. 5 


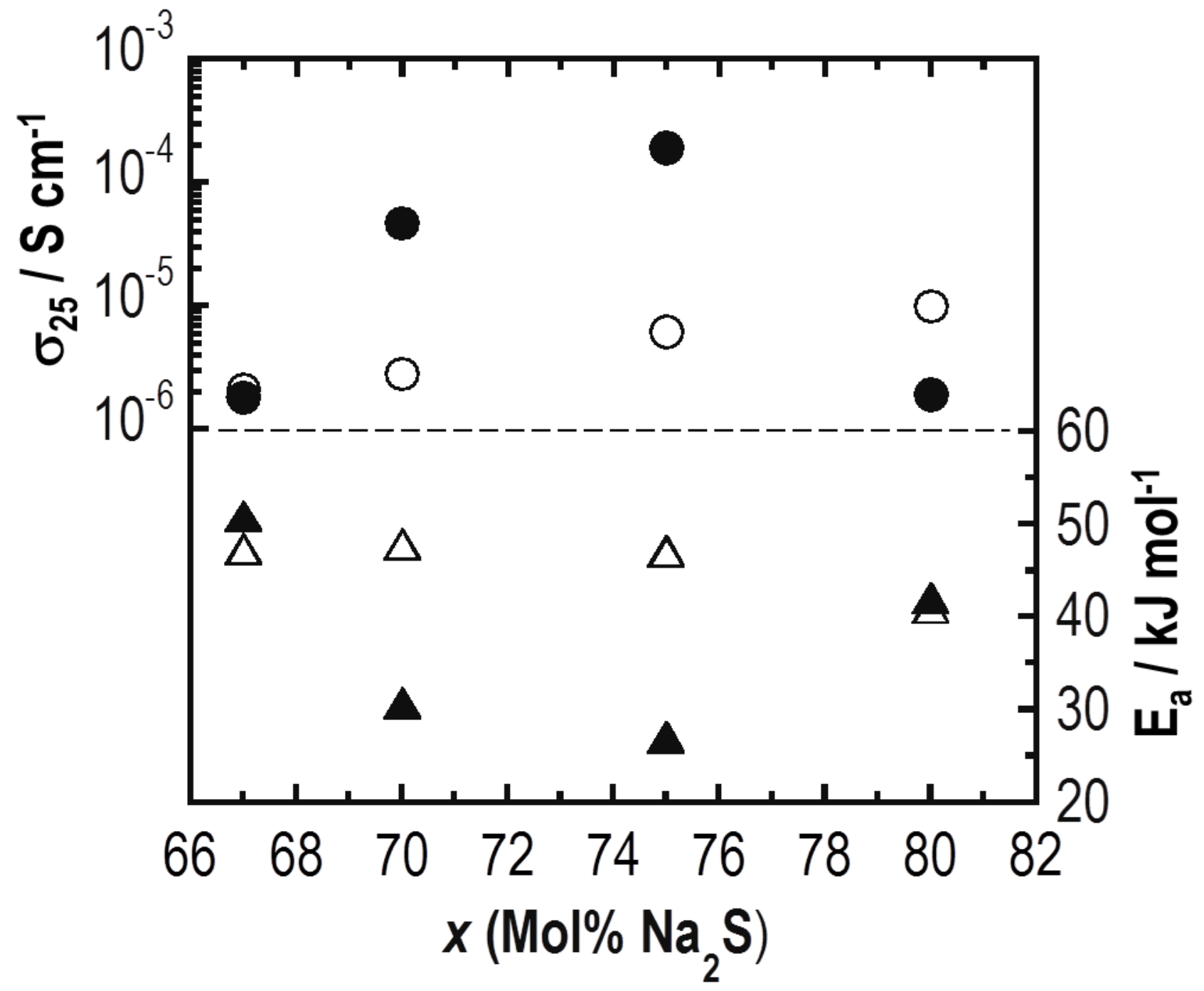

Fig. 6 


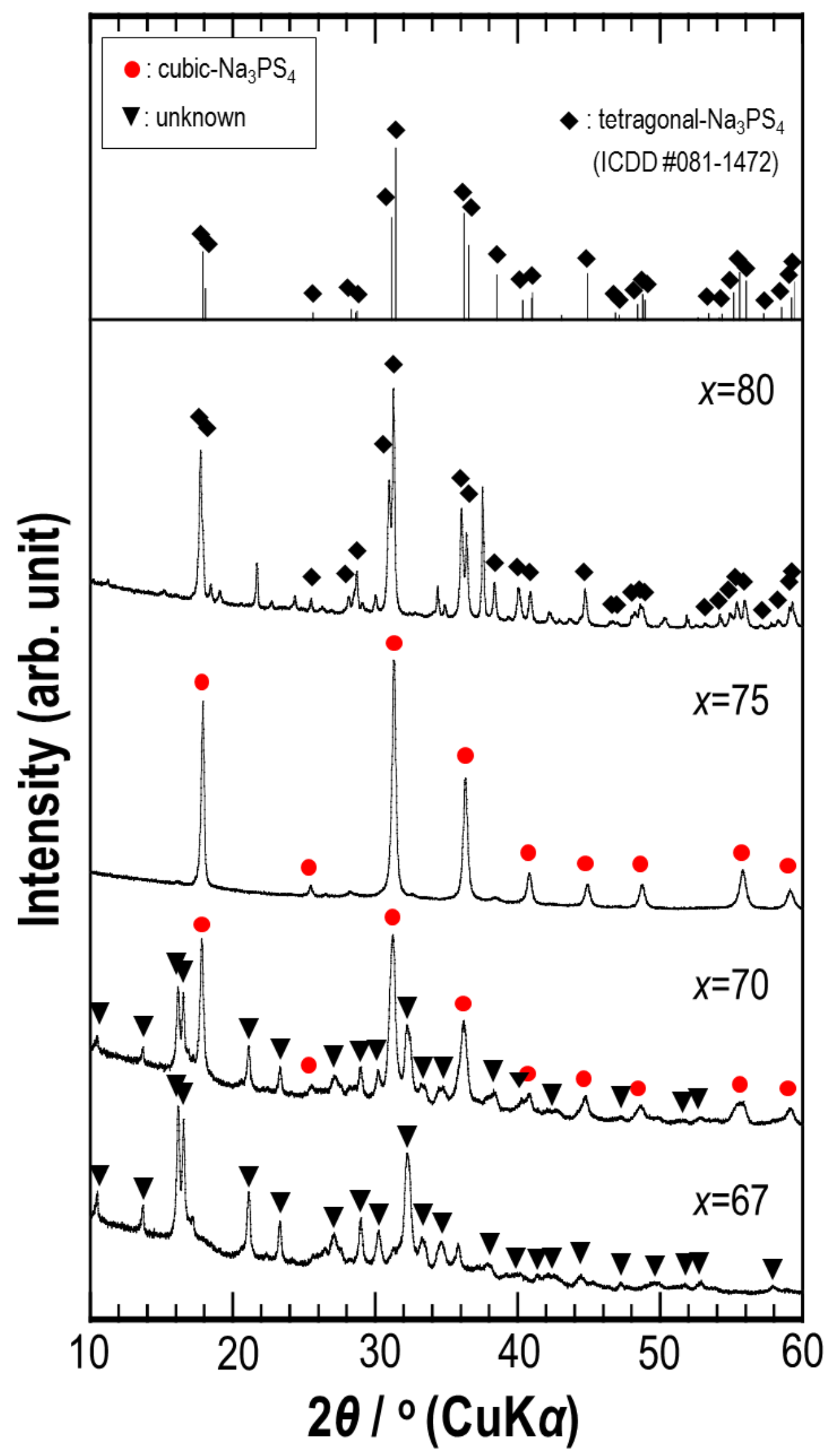

Fig. 7 


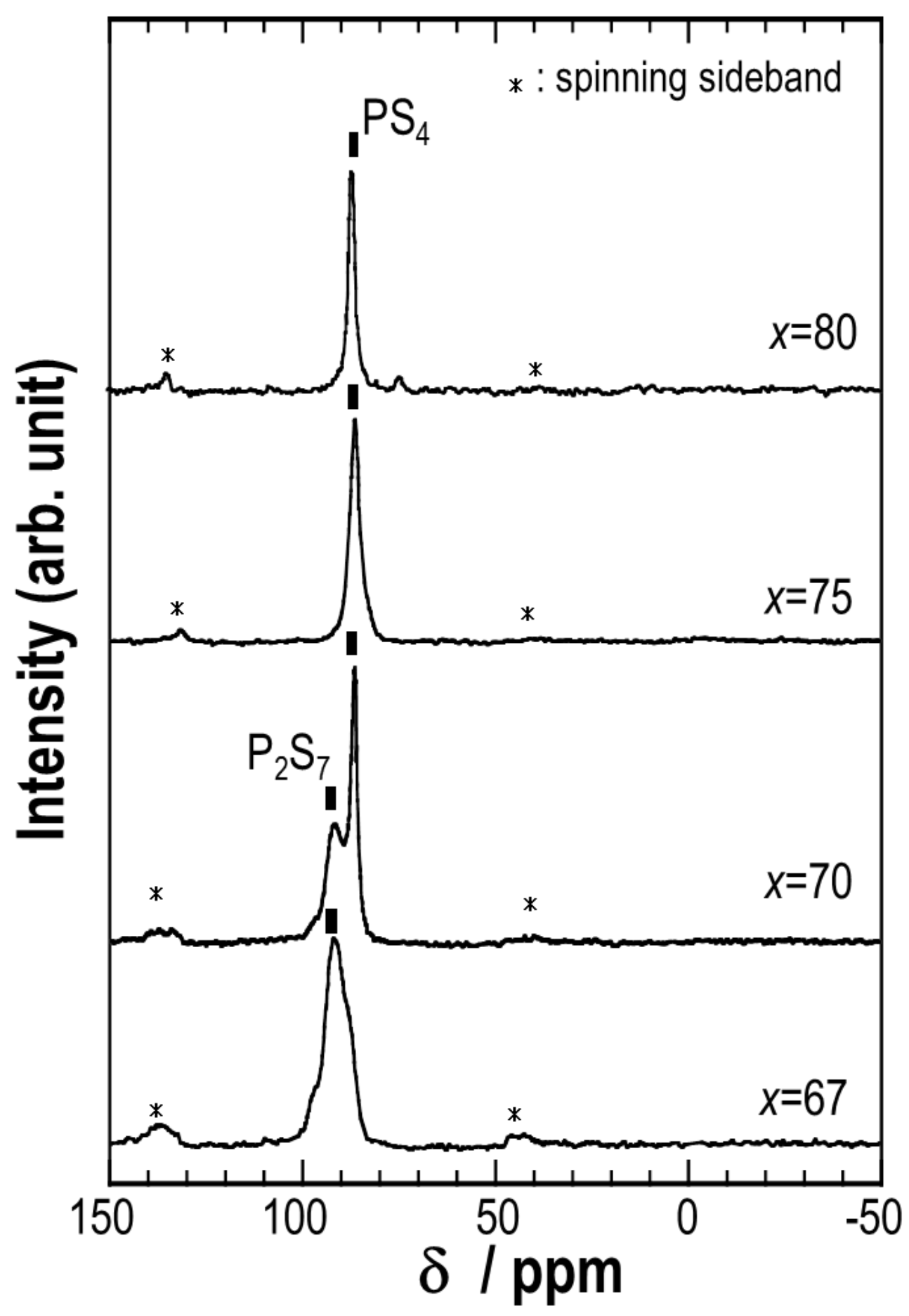

Fig. 8 


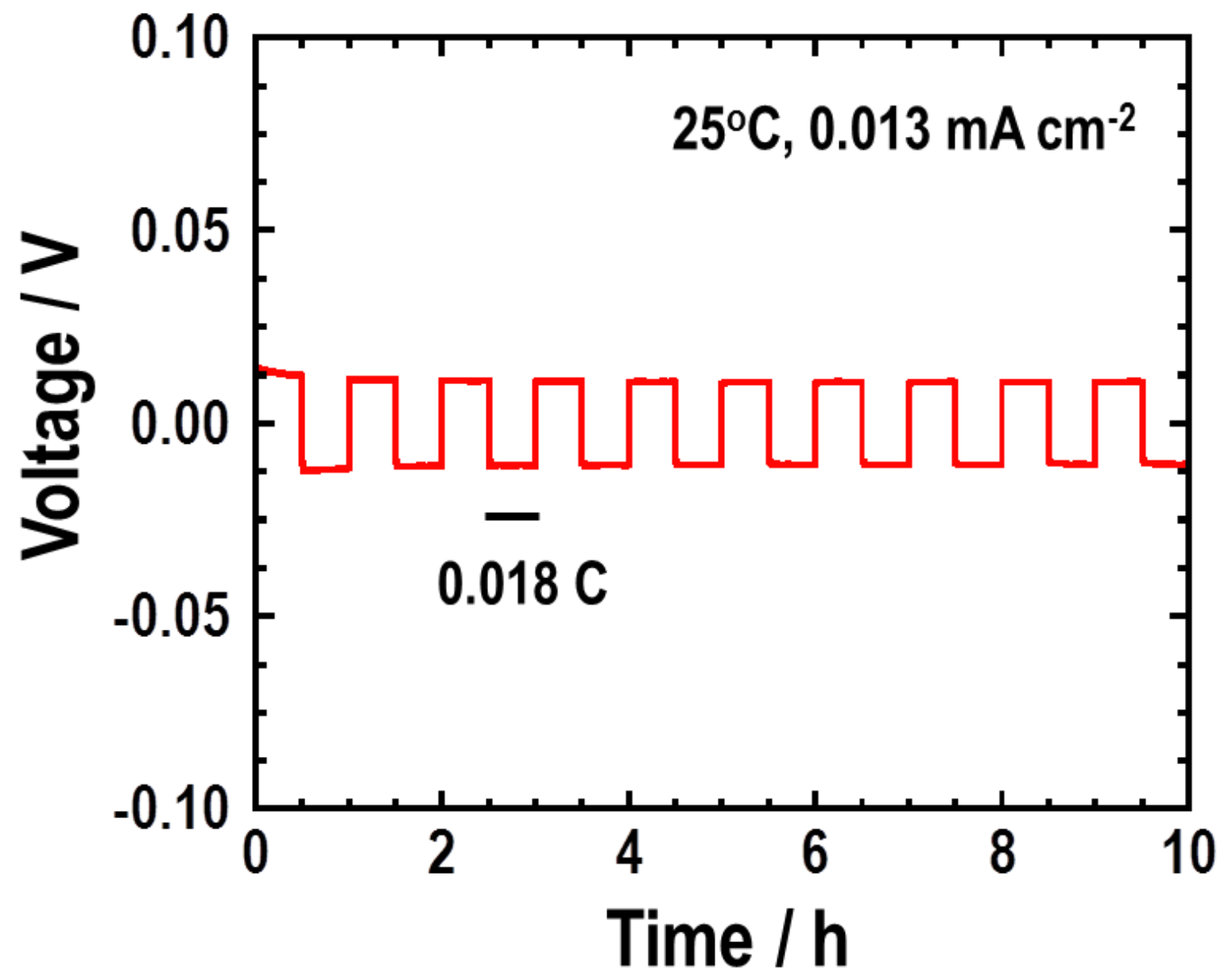

Fig. 9 


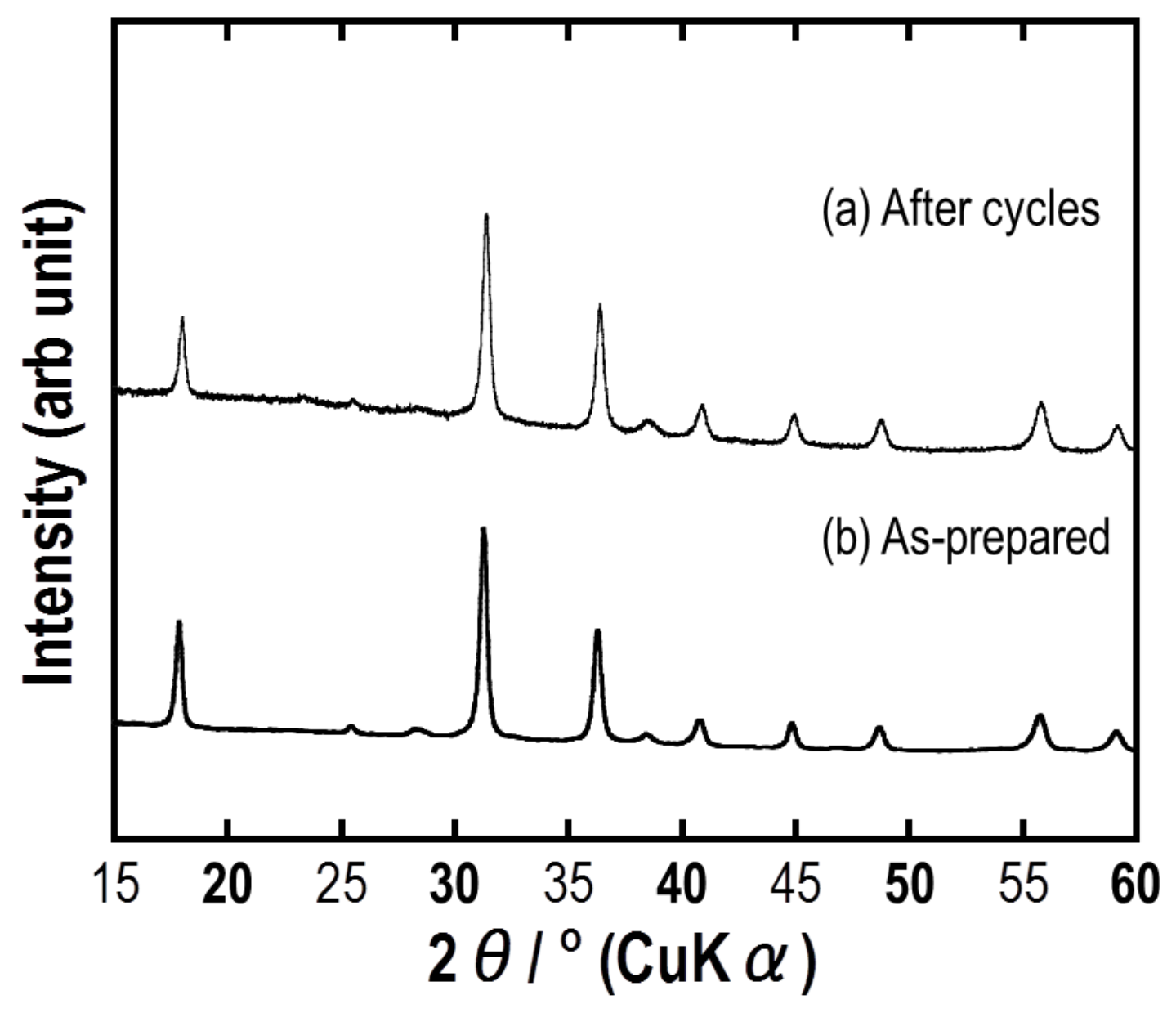

Fig. 10 